\title{
INFORMAÇÕES ESPACIAIS DE CARTAS ANTIGAS VISUALIZADAS EM IMAGENS DIGITAIS ATUAIS: UMA CONTRIBUIÇÃO DO SIG À ARQUEOLOGIA DA PAISAGEM
}

\author{
Marcos César Ferreira ${ }^{1}$ \\ Marta Felícia Marujo Ferreira ${ }^{2}$
}

Resumo: Este artigo apresenta uma metodologia baseada no Quantum GIS que permite a integração de imagens orbitais recentes, disponíveis no sistema Google Earth, a cartas históricas ou antigas. A pesquisa utiliza como exemplo de base cartográfica histórica a Carta Jaboticabal de 1927 (Carta 1927), produzida pela Comissão Geográfica e Geológica de São Paulo no mesmo ano e originalmente impressa na escala 1:100.000. Esta carta contém o posicionamento de sedes de fazendas, colônias de meeiros, capelas rurais, ramais ferroviários, estações ferroviárias, estradas, de rodagem e caminhos rurais, malhas urbanas e vilas. A Carta 1927 foi georreferenciada a uma imagem Google Earth de 2010, utilizando-se também como apoio cartográfico a Folha Jaboticabal, 1:50.000 do IBGE e coordenadas de alguns pontos de controle coletados em campo, com auxilio de um GPS Garmin 12 XL. Foram selecionados na imagem Google Earth, na carta 1:50.000 e em campo, pontos de controle que se mantiveram, desde o passado até o presente, na mesma posição geográfica e estavam também representados na Carta 1927. Em seguida, no Quantum GIS foi realizado o georreferenciamento da Carta 1927 utilizando-se o algoritmo de transformação polinomial de 2 a ordem, baseado no método de amostragem do vizinho mais próximo. Este procedimento permitiu o ajuste geométrico entre a Carta 1927 e a imagem Google. Em seguida, objetos representados na Carta 1927 foram digitalizados no formato vetorial no Quantum GIS, transformados em buffers, convertidos para o formato de arquivo KML $e$ sobrepostos diretamente à imagem de 2010, por meio do visualizador de imagens Google Earth. Este procedimento permitiu a localização de objetos que ainda permanecem no terreno na atualidade, desde 1927, objetos extintos, substituídos por outros usos, e os que permanecem apenas como fragmentos do passado.

Palavras-Chave - Geografia Histórica; SIG; Cartas Antigas; Arqueologia da Paisagem.

\section{Spatial information of old maps viewed in current digital images: a contribution of GIS to the landscape archeology}

\begin{abstract}
This paper presents a methodology based on Quantum GIS that allows the integration of recent satellite images to ancient or old maps The research uses as a basis the historical Jaboticabal topographical sheet of 1927 (1:100,000), produced by the Geographical and Geological Commission of São Paulo. This sheet give the positions of farmhouses; colonies, rural chapels, railway sidings, railway stations, roads, rural, urban networks and villages. In this paper, the topographical sheet of 1927 was georeferenced to the Google Earth image of 2010, based on GPS data and IBGE Jaboticabal sheet at 1:50,000 scale. Field control points that remained in the same geographical position since 1927 were selected. Then, in the GIS, it was applied a polynomial transformation, allowing a geometric

\footnotetext{
${ }^{1}$ Bacharel em Geografia pela UNESP, Mestre em Sensoriamento Remoto pelo INPE, Doutor em Geografia Física pela USP e Livre-Docente pela UNICAMP. Atualmente é Professor Associado do Instituto de Geociências da UNICAMP. E-mail: macferre@uol.com.br

${ }^{2}$ Bacharel em Geografia pela UNESP, Mestrado em Geografia Física pela USP e Doutorado em Geociências pela UNESP. Atualmente é professor adjunto da Universidade Federal de Alfenas. E-mail: martafelicia@uol.com.br DOI: 10.7154/RDG.2013.0026.0001
} 
adjustment between the old sheet and Google image. Landscape elements represented in 1927 were digitized and converted into buffers, and then, overlaid on the Google image. It was possible to map areas where is most likely to find nowadays objects built in 1927. This procedure allowed the location of objects that remain on the ground today, extinct objects, objects that remain as fragments of the past and those were replaced by others.

Key Words - Historical Geography; GIS; Ancient Maps; Landscape Archeology.

\section{INTRODUÇÃO}

A arqueologia da paisagem busca reconstituir a distribuição espacial do uso e ocupação do solo em tempos passados, a partir da combinação entre documentos cartográficos antigos, monografias históricas, mapas, informações espaciais recentes obtidas em campo e imagens de satélite. Talvez um dos maiores desafios metodológicos desta abordagem seja combinar cartas ou mapas atuais - construídos sobre projeções cartográficas e datum precisos - a documentos cartográficos antigos, que podem apresentar grande inexatidão geodésica, ausência de coordenadas espaciais, escala e projeção cartográfica.

Atualmente, a geografia tem se beneficiado das tecnologias de informação, sobretudo dos sistemas de informação geográfica (SIG) e das imagens de sensoriamento remoto, em diversas de suas disciplinas - em especial, na cartografia. O conhecimento das geotecnologias pode contribuir para a solução deste impasse gerado pela dificuldade de se realizar o ajuste entre as informações espaciais atuais e as pretéritas. Um exemplo de aplicação desta metodologia são as cartas-imagem históricas, que representam, sobre a camada da paisagem atual, objetos ou fragmentos de objetos socialmente construídos no passado. Este tipo de representação permite que o pesquisador realize associações cronogeográficas entre as organizações espaciais atuais e as pretéritas.

Os mapas históricos são documentos preciosos que mostram várias distribuições espaciais que tiveram relevância histórica no tempo em que foram construídos (SHIMIZU e FUSE, 2003). Ainda segundo estes autores, o método mais prático para a análise de mapas históricos em SIG é por meio da comparação com mapas atuais utilizando-se ferramentas de sobreposição de camadas. Contudo, em razão da baixa precisão geométrica de alguns mapas antigos, a comparação destes aos atuais pode se tornar tarefa muito difícil e trabalhosa.

Este artigo pretende dar uma pequena contribuição às pesquisas sobre cartográfica histórica apoiada em SIG, apresentando um procedimento simples baseado na combinação entre a Folha Topográfica Jaboticabal 1:100.000, produzida em 1927 (São Paulo, 1927) e uma 
imagem de satélite, do mesmo local, obtida em agosto de 2010 e disponível no sistema de visualização Google Earth.

\section{REVISÃO DA LITERATURA}

O campo de aplicações do SIG tem continuamente se ampliado nas últimas duas décadas. Além do seu uso tradicional na análise espacial, na gestão de recursos naturais, no monitoramento de sistemas ambientais e na gestão de cadastros urbanos, o SIG tem contribuído também com estudos relacionados à geografia histórica. O uso do SIG na geografia histórica - a que se denomina SIG histórico - permite a análise e o mapeamento de geografias do passado. Dentre as vantagens do uso do SIG neste campo do conhecimento, Gregory e Healey (2007) destacam a inclusão da localização explícita dos fatos passados, permitindo a análise de padrões e distribuições espaciais e o uso de camadas em sua base de dados, o que facilita a integração de mapas de diferentes datas.

Knowles (2005) reconhece o nascimento de uma nova geração de estudantes de geografia histórica, cujos conhecimentos estão sendo construídos com o auxílio do SIG. Segundo esta autora, conhecimento baseia-se no uso de técnicas de análise geoespacial para explorar relações espaciais e reconstruir lugares do passado e ambientes naturais pretéritos. Estas técnicas incluem desde a cartografia básica até formas mais sofisticadas de análise espacial e estatística espacial. Entre as abordagens geohistóricas que utilizam o SIG, Knowles destaca:

1. Reconstituição de limites administrativos e políticos, que historicamente são utilizados como referência para dados demográficos históricos (BERMAN, 2005);

2. Uso de softwares para diminuir a incerteza no posicionamento geográfico de localidades históricas e melhorar a precisão de dados históricos;

3. Combinação de diferentes fontes de dados (mapas antigos, entrevistas, documentos, dados de campo obtidos com GPS) para reconstruir a evolução do uso do solo e a modificação da paisagem.

4. Aplicação de técnicas geoestatísticas e de análise espacial - como operações booleanas e técnicas de overlay, entre outras - para calcular por meio de equações, a probabilidade de um valor ou evento ter ocorrido em uma determinada localidade. 
Com o objetivo de minimizar as limitações geométricas dos mapas antigos, Shimizu e Fuse (2003) utilizaram o método de correção geométrica, baseado em transformação polinomial, conhecido como rubber sheeting (WHITE; GRIFFIN, 1985), para sobrepor mapas de Tókio produzidos na era Edo (1603-1868), a mapas recentes. Este método baseia-se no seguinte pressuposto: mapas de diferentes épocas podem ser georreferenciados assumindo-se que os atributos topográficos da área não sofreram mudanças significativas durante o tempo que separa o mapa antigo do mapa mais atual. Desta forma, é possível realizar, inclusive, a sobreposição das curvas de nível de um mapa recente a um mapa antigo utilizando-se o seguinte procedimento: a) identificar pontos de controle (que não se moveram, do passado até o presente) localizados tanto no mapa antigo como no mapa atual; b) construir uma rede de triângulos conectando os pontos de controle, no mapa antigo e no mapa atual; c) aplicar uma transformação planar para cada par de triângulos.

As principais vantagens do uso desta metodologia são: a preservação das relações topológicas entre os objetos do mapa histórico e a maior coincidência espacial entre os pontos de controle do mapa histórico e os pontos de controle do mapa atual.

\section{MATERIAL E METODOLOGIA}

A metodologia adotada nesta pesquisa associa duas abordagens geohistóricas propostas por Knowles (2005): combinação entre diferentes fontes de dados (mapas antigos, entrevistas, documentos, dados de campo obtidos com GPS) para reconstruir a evolução do uso do solo e a modificação da paisagem; e, o uso de softwares para diminuir a incerteza no posicionamento geográfico de localidades históricas e melhorar a precisão de dados históricos.

A Carta de 1927, na escala 1:100.000 e originalmente em papel, foi digitalizada em scanner pelo método fotográfico, no formato milhões de cores, resolução $600 \mathrm{dpi}$. Desta folha topográfica foi selecionada uma área teste retangular com dimensões de $30 \mathrm{~km} \times 21 \mathrm{~km}$ (630 $\mathrm{km}^{2}$ ), cobrindo parte dos municípios de Jaboticabal, Monte Alto e Taiuva. Esta área foi rasterizada em uma grade de 7.010 colunas por 5.100 linhas, com pixels correspondendo a uma resolução média de 4,20 metros. Também foi considerada como fator determinante para a escolha desta área, a existência de maior número de objetos de interesse histórico e espacial - como ferrovias, estações ferroviárias, casas de colonos em fazendas, entre outros. 
A área teste foi georreferenciada no sistema de projeção Universal Transversa de Mercator (UTM), zona 22S, meridiano central $45^{\circ} \mathrm{W}$, datum SAD69 (South American Datum, 1969), por meio do módulo Georreferenciador do Quantum GIS 1.8.0, versão Lisboa (NANNI et al., 2013). Como referência sobre a organização espacial recente foi utilizado um recorte da imagem orbital do visualizador Google Earth, versão 6.0.2, de 27 de agosto de 2010, com as mesmas dimensões e idêntica localização da área selecionada na Carta1927.

Em seguida foram selecionados 52 pontos de controle, bem distribuídos por toda a Carta de 1927, localizados na intersecção de rios e afluentes visualizados tanto na Carta de 1927 como na imagem Google e na Folha Jaboticabal do IBGE (Brasil, 1971). Os 52 pontos foram posicionados sobre as mesmas feições hidrográficas (intersecção de rios e afluentes) visualizadas na Imagem Google Earth. Assim, um ponto posicionado na desembocadura de um rio, na Carta 1927, foi posicionado na mesma desembocadura visualizada na imagem de 2010 (Figura 1). A escolha por este tipo de feição da paisagem se deveu ao fato desta sofrer menor mudança espacial possível durante os 83 anos que separam a publicação da Carta de 1927 à imagem de 2010.

Como se trata de área situada sobre terrenos basálticos e colinosos, posicionados em planalto, e, as junções dos rios, escolhidas, situarem-se em canais de hierarquia inferior à de terceira ordem, consideramos que os erros de posicionamento destas desembocaduras em relação a 1927 foram muito pequenos em relação à escala de trabalho adotada. De posse dos valores das coordenadas dos pontos, iniciou-se a digitalização dos pontos de controle sobre a Carta 1927 não georreferenciada, com o uso da função Adicionar Ponto, do módulo Georreferenciador do Quantum GIS.

Foram testados todos os algoritmos disponíveis neste módulo, no sentido de escolher aquele que gerasse o menor erro médio possível. Dentre os testados, o que mostrou menor erro foi a transformação pelo polinômio de 2a ordem, associada ao método de reamostragem pelo vizinho mais próximo. Ao final deste teste foi gerada uma tabela GCP (ground control points), que apresenta os valores das coordenadas da Carta 1927, as respectivas coordenadas UTM, os desvios em $\mathrm{X}$ e $\mathrm{Y}$ e o resíduo, para os 52 pontos de controle.

O valor máximo, em metros, do resíduo estimado com os 52 pontos de controle utilizados na primeira fase do georreferenciamento foi utilizado como referência para a medida do raio dos buffers traçados em torno dos objetos da Carta 1927. Estes buffers foram 
posteriormente sobrepostos à imagem Google Earth de 2010, constituindo-se assim, em áreas de maior possibilidade de se encontrar, atualmente, objetos registrados na Carta 1927.

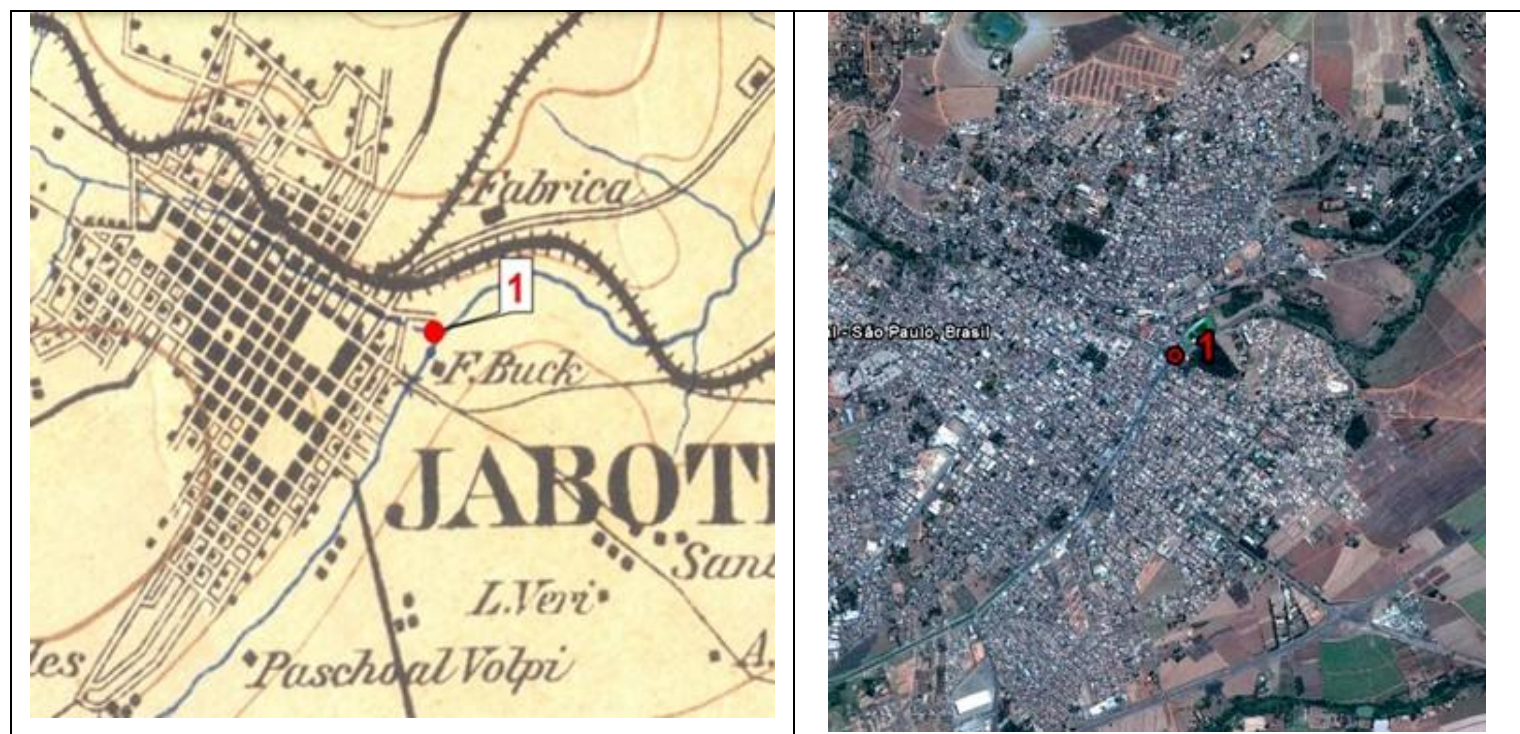

Figura 1 - Exemplo de seleção e posicionamento de um ponto de controle na Carta de 1927 (esquerda) e na imagem Google (direita). Sem escala.

A Carta 1927 constitui-se em um mapa-inventário da paisagem dos anos 1920, em uma região cafeeira do norte do estado de São Paulo, reunindo, em uma mesma camada, a justaposição de diversos níveis de informação. Nesta carta foram originalmente representados os seguintes temas: fazendas, capelas, topografia, estradas de carroças, estradas de automóvel, ferrovias, sítios e colônias, rede hidrográfica, estações ferroviárias e áreas urbanas.

Em razão da aglutinação de muitos temas em um só plano, esta representação original se constitui, segundo conceituação de Rouleau (1984), em um mapa para se ler. No mapa para se ler só é possível se obter respostas a perguntas do tipo "dentre todas as $n$ informações do mapa, qual delas ocorre aqui?" Por isto, a interpretação deste documento histórico permite que o leitor saiba o que existe em um ponto do mapa, impossibilitando-o de conhecer a distribuição espacial de cada fenômeno específico. Se quisermos obter soluções para questões do tipo "além daqui, onde também ocorre a informação i?", como a distribuição espacial específica das fazendas ou específica das ferrovias - teremos que construir mapas para se ver.

Com o intuito de produzir distribuições espaciais específicas, foi construída uma série de mapas analíticos - um para cada tema, isoladamente -armazenados em arquivo próprio, no formato de layers. Todos os mapas analíticos foram produzidos a partir da digitalização de feições vetoriais interpretadas sobre a Carta 1927 georreferenciada, utilizando-se o módulo 
de edição de shapes do Quantum GIS. A produção destas camadas foi realizada seguindo-se o seguinte procedimento:

a) Adição à tela do Quantum GIS, da camada raster correspondente a Carta 1927 georreferenciada ("Adicionar Camada Raster");

b) Criação de uma nova camada vetorial a ser produzida por meio de digitalização ("Camada>Novo>Nova Camada do tipo Shape");

c) Digitalização da nova camada vetorial ("Alternar Edição>Capturar Ponto, Linha ou Polígono").

Ao final de cada digitalização, um novo mapa temático contendo uma distribuição espacial específica foi produzido. Nesta etapa foram produzidos mapas analíticos das estações ferroviárias, sedes de fazendas, traçado das ferrovias, perímetros urbanos, capelas, engenhos e colônias.

\section{RESULTADOS E DISCUSSÃO}

As figuras 2 e 3 mostram, respectivamente, a área recortada da Carta 1927 e a localização dos 52 pontos utilizados no georreferenciamento. As linhas traçadas a partir dos pontos representam o grau de deslocamento de cada ponto, e os resíduos.

A Tabela 1 mostra os valores das coordenadas dos pontos de controle utilizados no georreferenciamento, os deslocamentos em $\mathrm{X}$ e $\mathrm{Y}$ e os respectivos resíduos.

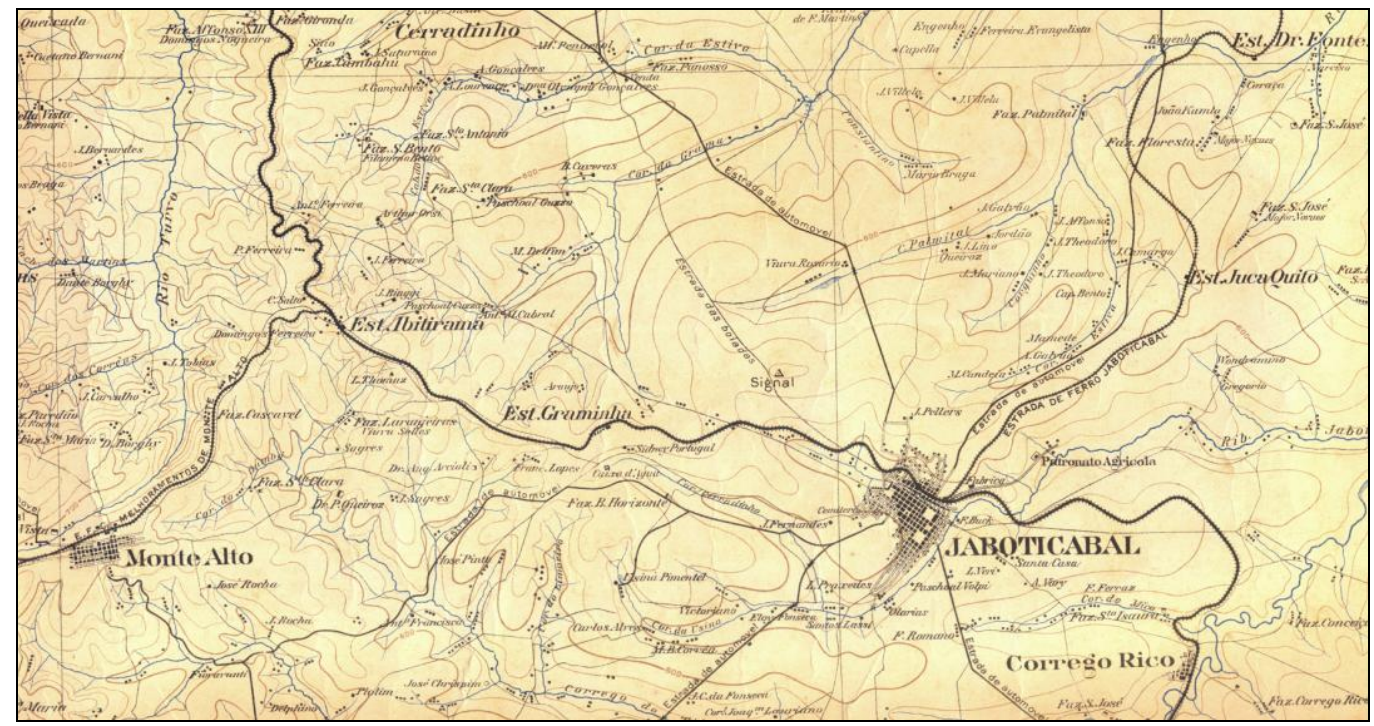

Figura 2 - Recorte da Folha Jaboticabal de 1927, utilizado como área teste. Fonte: adaptado de São Paulo (1927). 


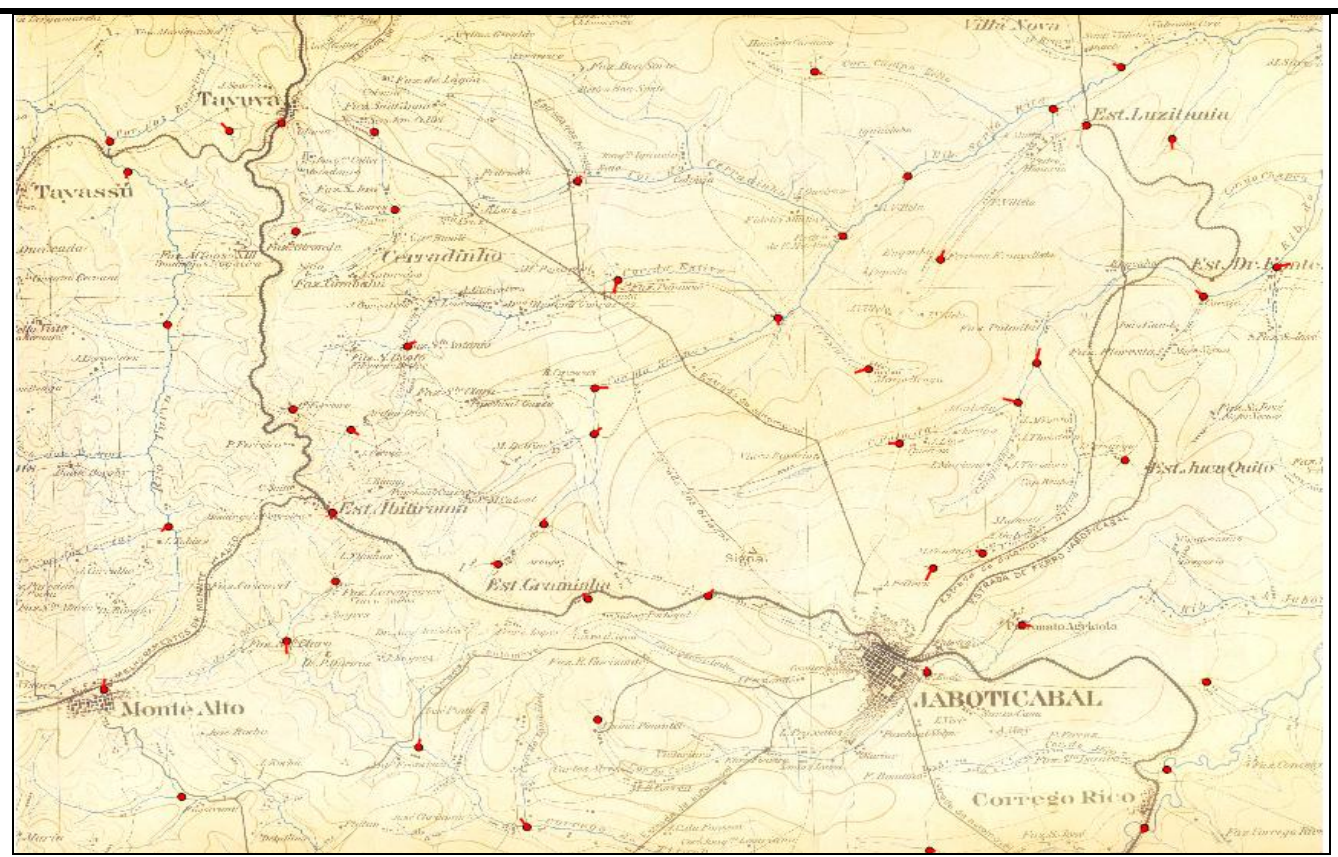

Figura 3 - Localização dos pontos de controle utilizados no georreferenciamento da Carta 1927. Os traços vermelhos próximos aos pontos representam o grau relativo de deslocamento espacial, expresso em valores de resíduo (Tabela 1).

A simulação do georreferenciamento com estes pontos resultou em um erro médio de 46,32 metros. Pontos que apresentaram valores muito elevados para o resíduo e o deslocamento foram excluídos; com esta estratégia, o erro médio diminuiu para 37,41 metros. A Figura 4 mostra a área teste, retirada da Carta 1927, georreferenciada no sistema de projeção cartográfica UTM.

Como exemplo da aplicação desta metodologia de sobreposição do espaço passado ao presente, apresentamos, na Figuras 5 o traçado de uma ferrovia, em funcionamento em 1927, representada sobre a imagem Google de 2010, indicando a posição que ocuparia, atualmente, em espaços ocupados por atividades canavieiras. Na Figura 6, o mesmo processo é aplicado para a determinação da localização mais provável, na imagem Google de 2010, de uma capela e um engenho, mapeados em 1927.

Tabela 1 - Valores das coordenadas UTM e matriciais dos pontos de controle utilizados para o georreferenciamento da Carta de 1927, e respectivos valores de deslocamento, e dos resíduos expressos em número de pixels e em metros.

\begin{tabular}{|c|c|c|c|c|cc|c|c|}
\hline \multirow{2}{*}{ Ponto } & \multicolumn{2}{|c|}{ Coordenadas UTM } & \multicolumn{2}{c|}{$\begin{array}{c}\text { Coordenada } \\
\text { Carta 1927 }\end{array}$} & \multicolumn{2}{|c|}{ Deslocamento } & $\begin{array}{c}\text { Res. } \\
\text { (pixels) }\end{array}$ & $\begin{array}{c}\text { Res. } \\
\text { (m) }\end{array}$ \\
\cline { 2 - 8 } & $\mathbf{E ~ ( m ) ~}$ & $\mathbf{N}(\mathbf{m})$ & $\mathbf{X}$ & $\mathbf{Y}$ & $\boldsymbol{\Delta}_{\mathbf{X}}$ & $\boldsymbol{\Delta}_{\mathbf{Y}}$ & & \\
\hline 1 & 781470 & 7648207 & 5393 & 3696 & 44,69 & 8,53 & 45,94 & 192,95 \\
2 & 779053 & 7647109 & 4884 & 3982 & 0,65 & $-23,37$ & 23,38 & 98,20 \\
3 & 779126 & 7649449 & 4916 & 3353 & $-31,87$ & 70,81 & 77,65 & 326,13 \\
4 & 780998 & 7654197 & 5371 & 2351 & $-70,44$ & $-17,20$ & 72,65 & 305,13 \\
5 & 781814 & 7655511 & 5472 & 2113 & 17,61 & $-79,79$ & 81,71 & 343,18 \\
\hline
\end{tabular}




\begin{tabular}{|c|c|c|c|c|c|c|c|c|}
\hline 6 & 787565 & 7657856 & 6759 & 1534 & 73,33 & $-14,65$ & 74,78 & 314,08 \\
\hline 7 & 784813 & 7660839 & 6199 & 758 & 3,52 & 60,29 & 60,40 & 253,68 \\
\hline 8 & 782137 & 7661759 & 5560 & 577 & 24,37 & 15,28 & 29,01 & 121,84 \\
\hline 9 & 777190 & 7658482 & 4432 & 1346 & $-15,82$ & $-5,21$ & 16,66 & 69,97 \\
\hline 10 & 775804 & 7656150 & 4083 & 1841 & 7,39 & 41,92 & 42,56 & 178,75 \\
\hline 11 & 777589 & 7654890 & 4569 & 2149 & $-63,46$ & 24,17 & 67,91 & 285,22 \\
\hline 12 & 771846 & 7654555 & 3100 & 2266 & 68,73 & $-1,30$ & 68,74 & 288,71 \\
\hline 13 & 771693 & 7653497 & 3097 & 2542 & 38,40 & $-30,86$ & 49,26 & 206,89 \\
\hline 14 & 770367 & 7651169 & 2826 & 3087 & 8,79 & $-26,74$ & 28,15 & 118,23 \\
\hline 15 & 769124 & 7650049 & 2581 & 3329 & $-29,02$ & $-0,24$ & 29,02 & 121,88 \\
\hline 16 & 765426 & 7649703 & 1708 & 3432 & $-14,83$ & 8,44 & 17,07 & 71,69 \\
\hline 17 & 764321 & 7647927 & 1446 & 3793 & 3,64 & 73,83 & 73,91 & 310,42 \\
\hline 18 & 767295 & 7645525 & 2155 & 4436 & 9,43 & $-40,27$ & 41,36 & 173,71 \\
\hline 19 & 769525 & 7643367 & 2736 & 4917 & $-26,99$ & $-44,07$ & 51,67 & 217,01 \\
\hline 20 & 771428 & 7645825 & 3115 & 4268 & 7,69 & 23,12 & 24,37 & 102,35 \\
\hline 21 & 784538 & 7644329 & 6170 & 4569 & 18,07 & 13,73 & 22,69 & 95,30 \\
\hline 22 & 761704 & 7644307 & 883 & 4734 & $-4,69$ & 9,42 & 10,53 & 44,23 \\
\hline 23 & 761546 & 7651197 & 813 & 3102 & $-31,51$ & 27,47 & 41,81 & 175,60 \\
\hline 24 & 766103 & 7653489 & 1791 & 2517 & 42,02 & 30,94 & 52,17 & 219,11 \\
\hline 25 & 766889 & 7659247 & 2028 & 1187 & $-9,97$ & $-0,04$ & 9,97 & 41,87 \\
\hline 26 & 760323 & 7661267 & 498 & 775 & $-2,60$ & $-22,87$ & 23,01 & 96,64 \\
\hline 27 & 760749 & 7660242 & 594 & 958 & $-4,28$ & 35,47 & 35,73 & 150,07 \\
\hline 28 & 761748 & 7656371 & 806 & 1881 & 9,27 & 24,25 & 25,97 & 109,07 \\
\hline 29 & 762924 & 7661525 & 1139 & 711 & $-35,77$ & $-40,31$ & 53,89 & 226,34 \\
\hline 30 & 766366 & 7661273 & 1918 & 717 & $-13,95$ & $-6,55$ & 15,41 & 64,72 \\
\hline 31 & 776672 & 7662658 & 4280 & 353 & 35,81 & 14,50 & 38,64 & 162,29 \\
\hline 32 & 783409 & 7663002 & 5925 & 326 & $-35,80$ & $-14,43$ & 38,60 & 162,12 \\
\hline 33 & 785429 & 7657096 & 6366 & 1710 & $-32,79$ & $-28,55$ & 43,48 & 182,62 \\
\hline 34 & 778651 & 7659979 & 4780 & 984 & $-17,24$ & 11,08 & 20,50 & 86,10 \\
\hline 35 & 783775 & 7652680 & 5945 & 2701 & 6,03 & $-15,04$ & 16,21 & 68,08 \\
\hline 36 & 778351 & 7653027 & 4734 & 2599 & $-47,62$ & 3,28 & 47,73 & 200,47 \\
\hline 37 & 782761 & 7661308 & 5739 & 676 & $-12,26$ & 23,75 & 26,72 & 112,22 \\
\hline 38 & 774194 & 7649227 & 3708 & 3522 & 29,24 & $-32,30$ & 43,57 & 182,99 \\
\hline 39 & 771211 & 7649191 & 3064 & 3540 & $-20,32$ & $-25,57$ & 32,66 & 137,17 \\
\hline 40 & 765451 & 7651360 & 1693 & 3017 & $-3,07$ & 35,59 & 35,73 & 150,07 \\
\hline 41 & 760101 & 7647436 & 467 & 4086 & 5,14 & $-53,85$ & 54,10 & 227,22 \\
\hline 42 & 764300 & 7661576 & 1419 & 664 & 5,30 & $-14,16$ & 15,12 & 63,50 \\
\hline 43 & 783822 & 7642711 & 6051 & 4922 & $-9,01$ & 26,43 & 27,93 & 117,31 \\
\hline 44 & 767428 & 7655826 & 2095 & 2012 & 43,19 & $-22,67$ & 48,78 & 204,88 \\
\hline 45 & 764674 & 7654211 & 1479 & 2394 & 19,38 & -4.47 & 19.89 & 83,54 \\
\hline 46 & 771200 & 7660012 & 3007 & 1015 & 18,49 & $-24,45$ & 30,65 & 128,73 \\
\hline 47 & 772017 & 7657028 & 3224 & 1612 & $-16,36$ & 74,79 & 76.56 & 321,55 \\
\hline 48 & 778988 & 7642252 & 4897 & 5059 & 27,14 & 6,04 & 27,80 & 116,76 \\
\hline 49 & 779601 & 7658066 & 4956 & 1488 & 21,46 & $-48,69$ & 53,21 & 223,48 \\
\hline 50 & 780313 & 7650187 & 5181 & 3263 & $-25,51$ & $-9,96$ & 27,39 & 115,04 \\
\hline 51 & 764659 & 7658788 & 1495 & 1319 & 1,40 & $-9,46$ & 9,57 & 40,19 \\
\hline 52 & 785418 & 7646758 & 6384 & 4041 & $-15,22$ & $-6,07$ & 16,38 & 68,80 \\
\hline
\end{tabular}




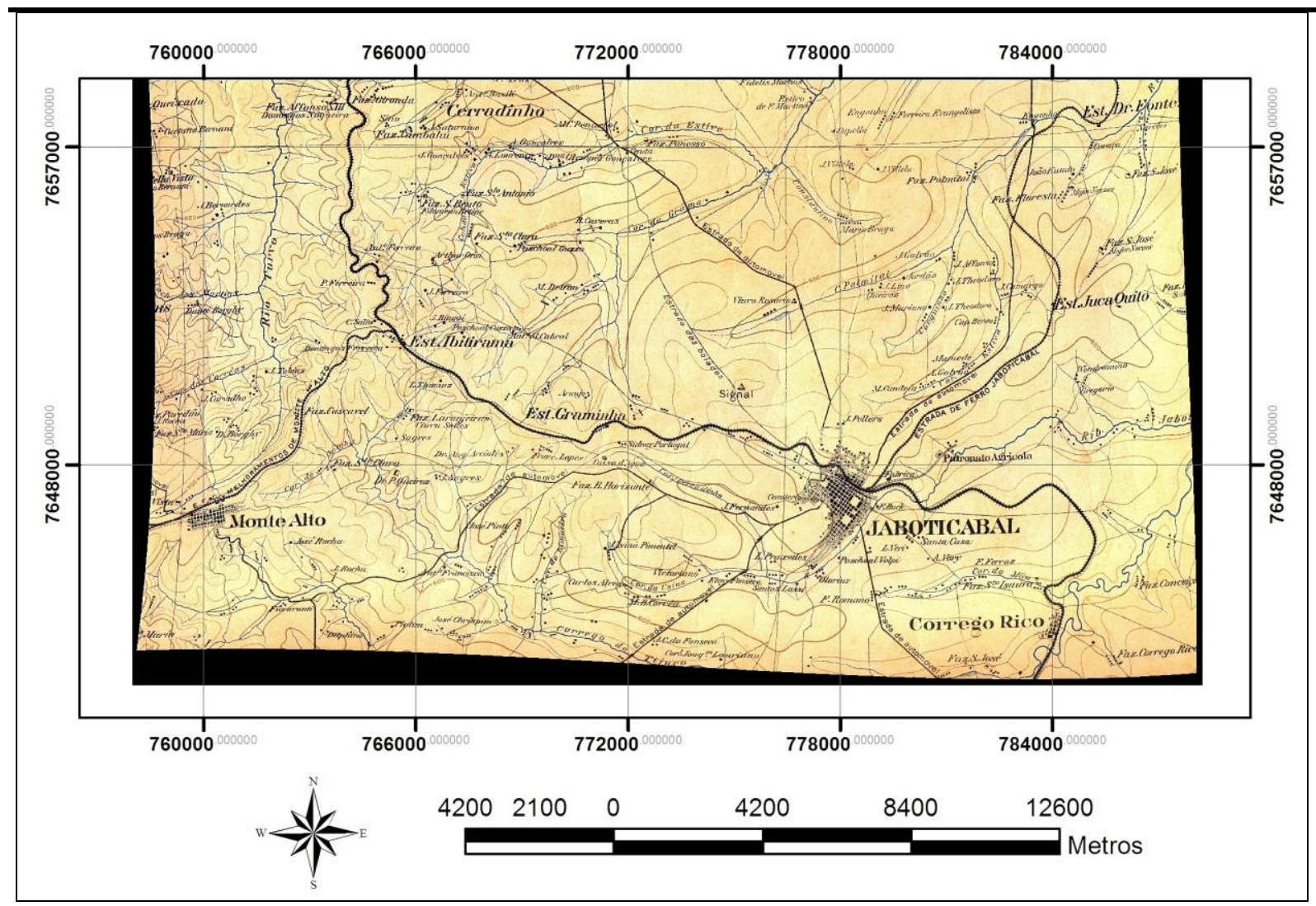

Figura 4 - Recorte da Folha Jaboticabal de 1927, georreferenciado no sistema de projeção UTM, pelo método polinomial rubber sheeting.

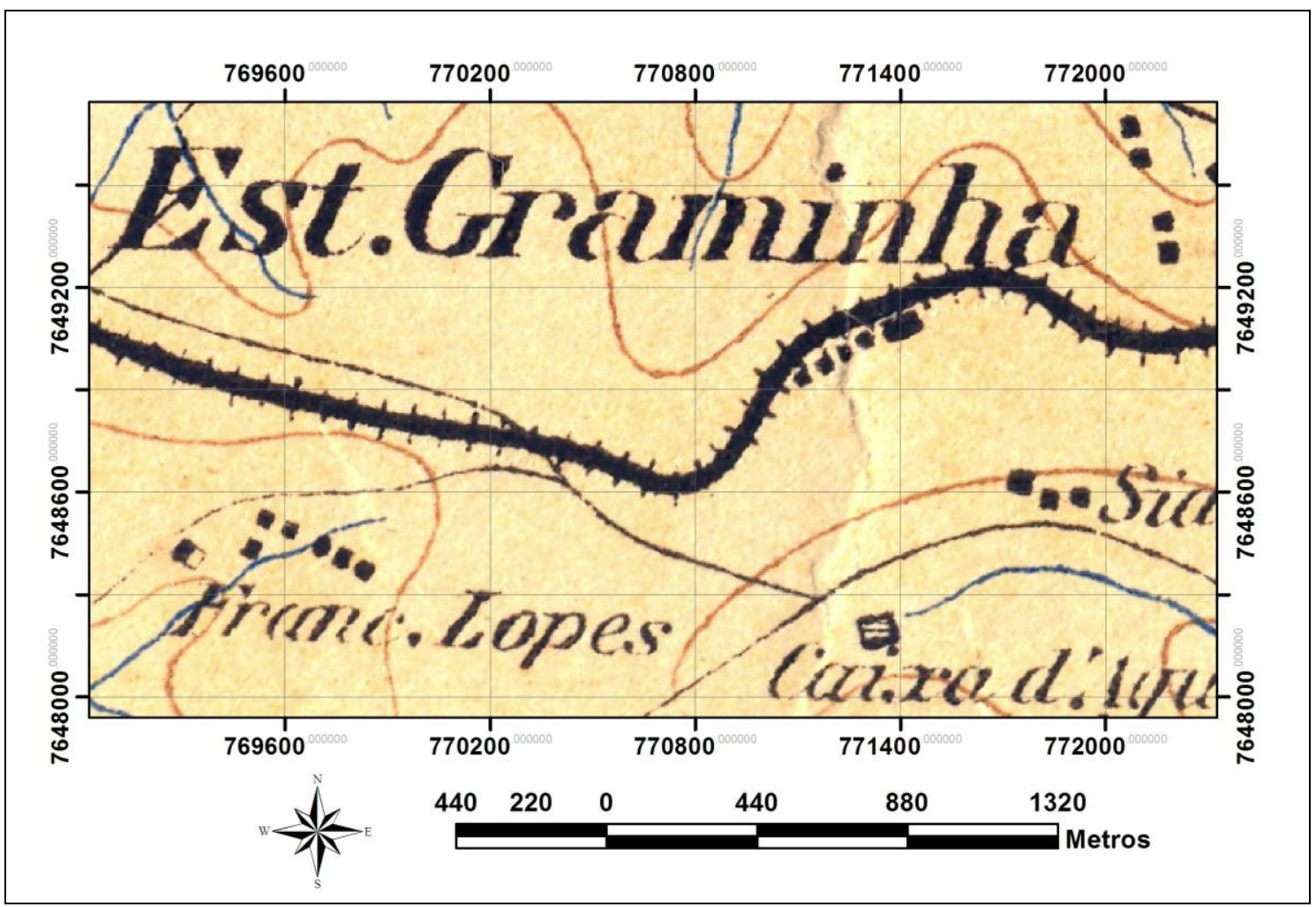




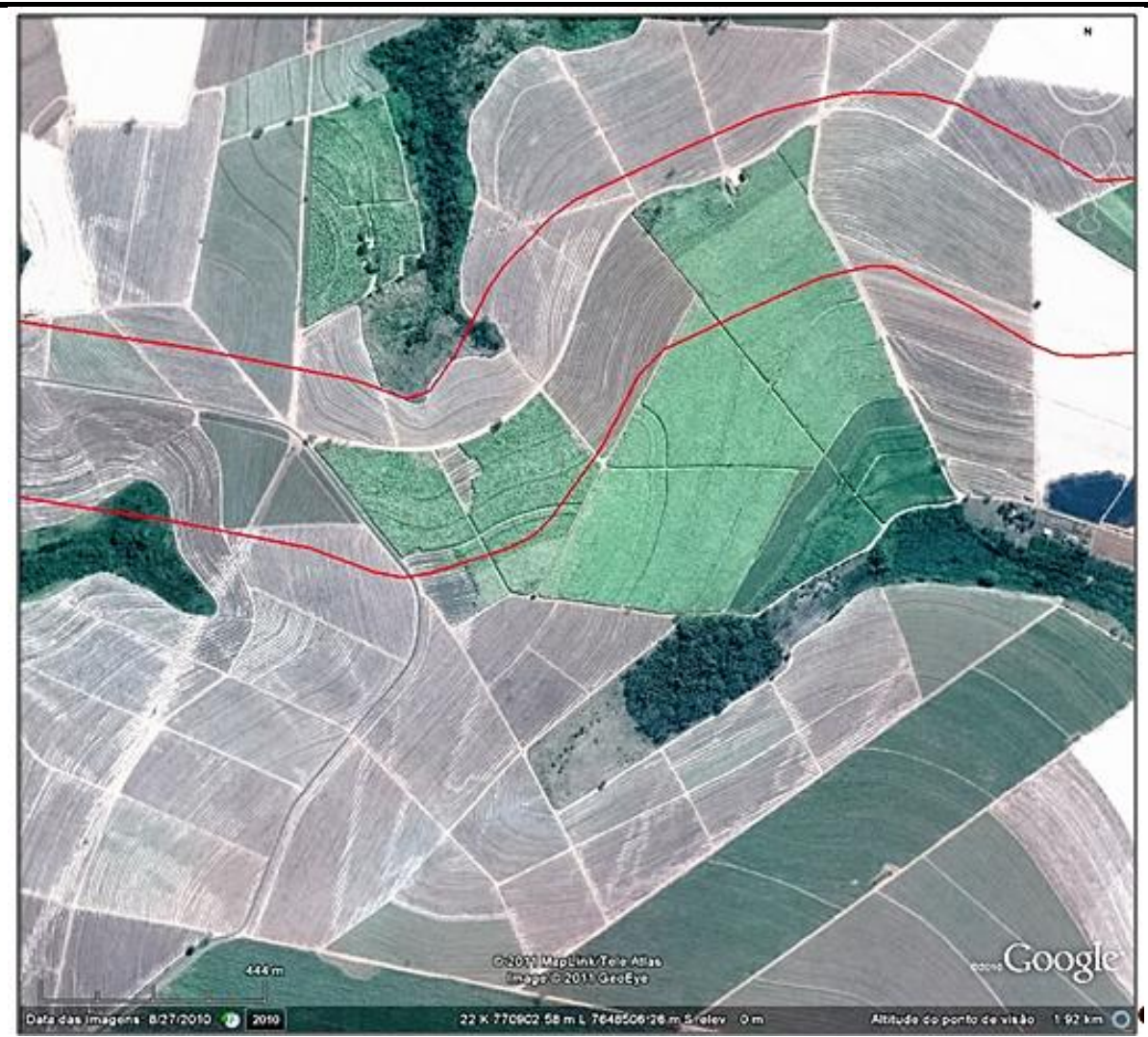

Figura 5 - Acima, detalhe da localização de um segmento ferroviário da Companhia Paulista de Estradas de Ferro, situado entre Jaboticabal e Taiuva, e registrado na Carta 1927, próximo à estação Graminha. Abaixo, o traçado do buffer em torno do mesmo segmento, indicando em seu centro, a localização atual do traçado ferroviário - hoje transformado em estrada rural não pavimentada, cortando áreas canavieiras.

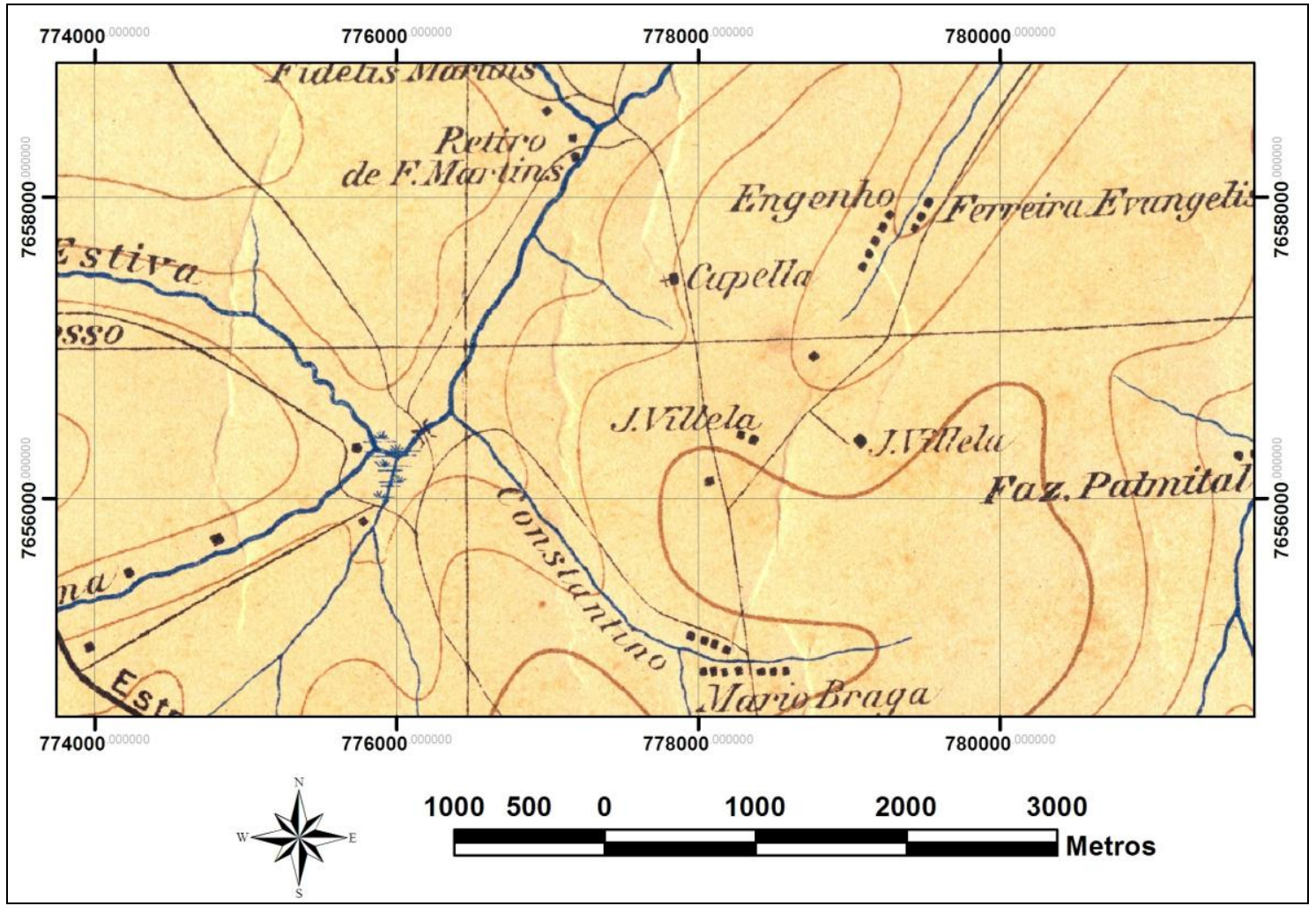




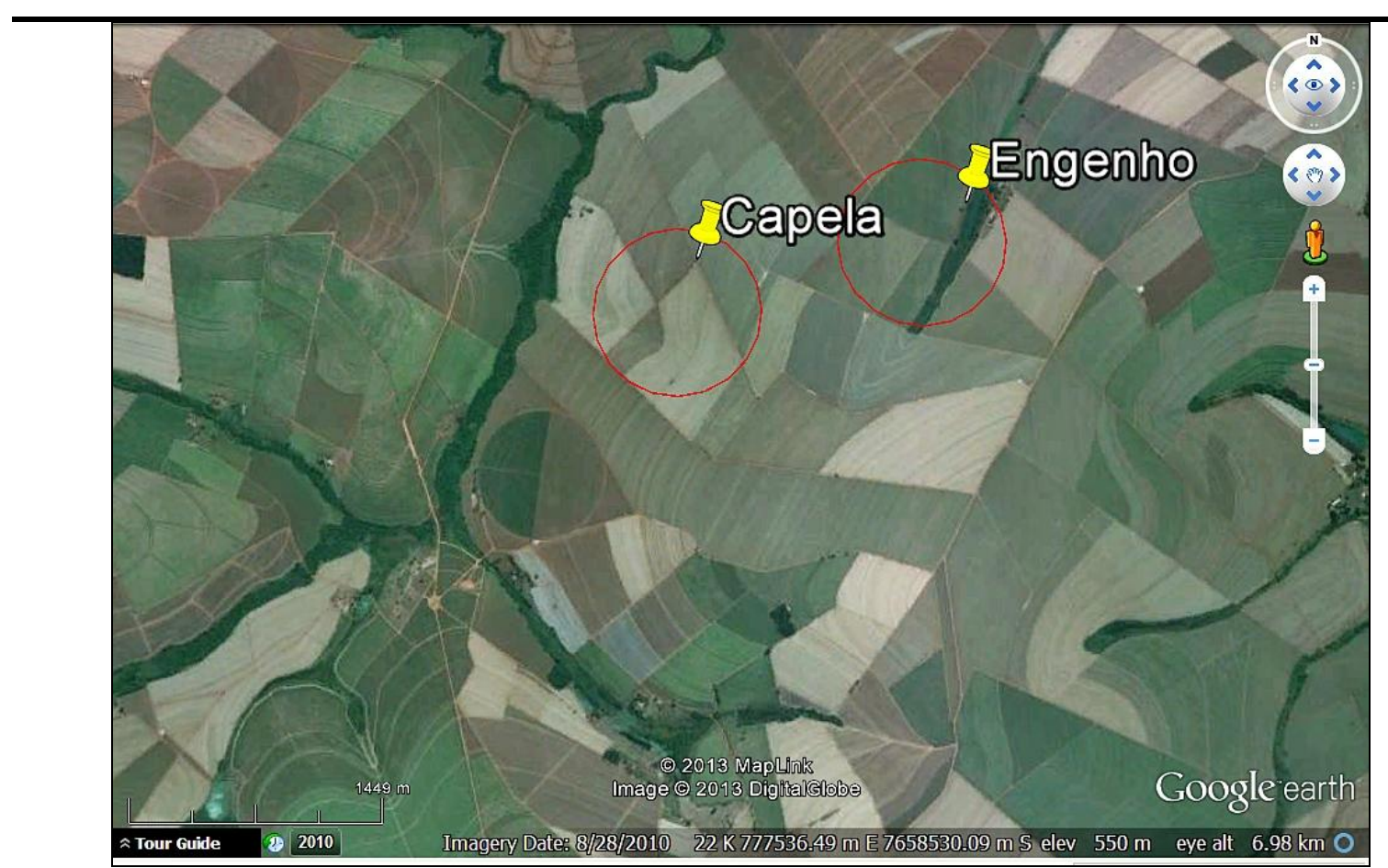

Figura 6 - A capela ("capella", na Carta 1927) e o engenho - localizados na porção central da Carta 1927 (acima), e destacados por ponteiros amarelos na imagem Google - foram posicionados dentro dos respectivos buffers e sobrepostos à imagem Google Earth de 2010 (abaixo). Os círculos em vermelho representam as áreas mais prováveis de se encontrar, atualmente, no campo, a capela e o engenho mapeados em 1927.

A precisão do georreferenciamento entre mapas e imagens de satélite depende principalmente de fatores geográficos e geométricos da cena terrestre representada. 0 sucesso desta transformação depende da qualidade dos pontos de controle utilizados. Especificamente nos ajustes entre cartas antigas e imagens atuais - situação em que há grandes diferenças tecnológicas entre os processos utilizados para a construção de ambas as representações espaciais - a interpretação dos resultados deve ser conduzida de maneira distinta daquela adotada em processos convencionais de georreferenciamento.

No caso específico deste trabalho, embora a Carta 1927 utilizasse como origem das medidas de longitude o meridiano do Rio de Janeiro, o número de pontos com coordenadas disponíveis é muito pequeno para que se possa fazer uso deles como pontos de controle para o georreferenciamento. Entretanto, se a área mapeada é extensa, esta é uma alternativa que pode ser utilizada e testada para se averiguar o erro médio do georreferenciamento.

Deve-se considerar que o posicionamento dos objetos geográficos em algumas cartas antigas, é, muitas vezes, relativo e baseado também em atributos de vizinhança, além, propriamente, de atributos geodésicos de posição. Por isto, deve-se interpretar a localização atual daqueles objetos no terreno e nas imagens, de forma relativa, baseada em faixas em 
torno de pontos ou de linhas, indicando a posição atual mais provável dos objetos representados em cartas antigas.

Utilizamos a imagem do sistema Google Earth em razão de sua maior acessibilidade e difusão social - fatores que facilitam o seu uso por pesquisadores não especializados em sensoriamento remoto ou que tenham como objetivo maior a análise geohistórica de um determinado território. Contudo, sugere-se que a imagem Google seja georreferenciada a uma carta topográfica, antes de se iniciar a aplicação da metodologia aqui proposta.

\section{CONSIDERAÇÕES FINAIS}

O uso desta metodologia de ajuste geométrico entre a carta topográfica produzida em 1927 e a imagem de alta resolução de 2010 permitiu o uso compartilhado entre informações geohistóricas de elementos da paisagem, que caracterizavam as duas primeiras décadas do século XX, e a configuração espacial desta mesma área, na primeira década do século XXI. Informações pontuais de 1927 - como fazendas antigas, estações ferroviárias hoje demolidas e capelas situadas na zona rural - mostraram melhor ajuste em relação à sua posição geográfica atual. Este fato contribui para a melhor identificação, em campo, destas construções (ou de sua inexistência atual) dentro dos buffers traçados no SIG.

Já as informações lineares, como o traçado de ferrovias e estradas rurais do início do século XX, apresentaram precisão geométrica mais limitada. Em algumas áreas da imagem a sobreposição de feições lineares antigas às atuais foi mais precisa, mas em outras, não. Isto se deve, entre outros fatores, à menor precisão no posicionamento de linhas na Carta de 1927, em razão de restrições técnicas daquele período. Além deste fator limitante, consideramos também que o modelo de correção geométrica utilizado nesta pesquisa (polinomial de $2^{a}$ ordem, pelo vizinho mais próximo) pode ter comportamento diferente a depender do tipo de informação geohistórica considerada. Por isto, daremos continuidade à pesquisa, avaliando o desempenho de outros métodos de interpolação, apoiados por um maior número de pontos de controle em campo.

De maneira geral, concluímos que esta metodologia pode contribuir ao conhecimento da configuração espacial de paisagens pretéritas, construídas em períodos tecnológicos remotos, e auxiliar a identificação de locais de interesse histórico representados em cartas e situados em áreas rurais atuais. Salientamos que os resultados obtidos pela aplicação desta metodologia devem ser interpretados de forma relativa, pois indicam na imagem Google de 
2010, áreas onde há a maior chance de se encontrar atualmente objetos edificados no passado e representados na Folha Jaboticabal de 1927.

\section{REFERÊNCIAS BIBLIOGRÁFICAS}

BERMAN, M. L. Boundaries or networks in historical GIS: concepts of measuring space and administrative geography in Chinese history. Historical Geography, 33: 118-133, 2005.

BRASIL. Instituto Brasileiro de Geografia e Estatística. Folha Topográfica Jaboticabal, escala 1:50.000, 1971.

GREGORY, I. N.; HEALEY, R. G. Historical GIS: structuring, mapping and analyzing geographies of the past. Progress in Human Geography, 31(5):638-653, 2007.

KNOWLES, A. K. Emerging trends in historical GIS. Historical Geography, 33:7-13, 2005.

NANNI, A. S. et al. Quantum GIS. Guia do usuário. Versão 1.8.0. Disponível em http://qgisbrasil.org, 291p. Acessado em 10 de março de 2013.

ROULEAU, B. Theory of cartographic expression and design. In: ICC - Basic cartography for students and technicians, London, ICC, 1984.

SÃO PAULO. Comissão Geographica e Geologica do Estado de S. Paulo, Brazil - Folha Jaboticabal: edição preliminar. Seção Catographica da Companhia Melhoramentos, São Paulo, Cayeiras, 1927.

SHIMIZU, E.; FUSE, T. Rubber-sheeting of historical maps in GIS and its application to landscape visualization of old-time cities: focusing on Tokyo of the past. Proceedings of the 8th International Conference in Urban Planning and Urban Management, Sendai, Japan, 2003.

WHITE, M.S.; GRIFFIN, P. Piecewise linear rubber-sheet map transformations. The American Cartographer, 12(2):123-131, 1985.

Artigo recebido em 03/08/2013.

Artigo aceito em 06/09/2013. 